\title{
Can E12 sheet plastination be used to examine the presence and incidence of intra-articular spinal meniscoids?
}

\author{
Scott F. Farrell ${ }^{1}$, Peter G. Osmotherly ${ }^{1}$, Darren A. Rivett ${ }^{1}$, Jon Cornwall ${ }^{2}$ \\ ${ }^{1}$ Discipline of Physiotherapy, School of Health Sciences, The University of Newcastle, Newcastle, Australia \\ ${ }^{2}$ Departments of Anatomy and Physiology, and Faculty of Law, University of Otago, Dunedin, New Zealand
}

\begin{abstract}
Objectives: The role of intra-articular meniscoids in spinal pathology is unclear, and their anatomy not well understood. Spinal meniscoids have been identified in research using dissection and imaging. No previous studies have identified these structures using E12 sheet plastination; such methods of visualising meniscoids are likely of value in research and education. Our aim was to examine the presence of spinal meniscoids in cadaver sections that had undergone E12 sheet plastination.

Methods: The lateral atlantoaxial and cervical, thoracic and lumbar zygapophyseal joints were inspected in two female cadavers $(65,86$ years) that had undergone E12 sheet plastination in $2 \mathrm{~mm}$ sagittal and transverse sections. Each slice was photographed on a light-box then inspected under magnification to identify individual joints, then each joint assessed for the presence of meniscoids.

Results: From 281 photographs, 92 zygapophyseal and four lateral atlantoaxial joints were identified. In sagittal sections, 24 meniscoids were identified in atlantoaxial and cervical joints and 32 meniscoids in the thoracic spine. In transverse sections, 14 meniscoids were identified in the thoracic spine and 12 meniscoids in the lumbar spine. Meniscoids were identified in all atlantoaxial and cervical joints, $78.9 \%$ of thoracic joints, and $80 \%$ of lumbar joints.

Conclusion: Spinal meniscoids were effectively visualised on E12 sheet plastinates in all spinal regions. Meniscoid frequency was similar to previous reports for the atlantoaxial and cervical joints, and higher for thoracic and lumbar joints. Sheet plastinations can therefore be utilised in research and education exploring the anatomy and clinical significance of the meniscoids.
\end{abstract}

Keywords: E12 sheet plastination; meniscoid; spinal meniscoid, spine

Anatomy 2015;9(1):13-18 @2015 Turkish Society of Anatomy and Clinical Anatomy (TSACA)

\section{Introduction}

Intra-articular spinal meniscoids are folds of synovial membrane that extend between the articular surfaces of the zygapophyseal and lateral atlantoaxial joints (Figure 1)..$^{[1-4]}$ These structures are thought to compensate for incongruence of the articulating cartilages, and to ensure the lubrication of the articular surfaces with synovial fluid. ${ }^{[1,2]}$ Intraarticular spinal meniscoids in all regions of the spine have been described in anatomical research undertaken by dissection and by imaging, ${ }^{[1,2-6]}$ however their morphology and role in pathology are not well understood. It has been suggested that spinal meniscoids have a role in spinal patholo- gy, including through articular degeneration, ${ }^{[3,7,8]}$ mechanical entrapment, ${ }^{[1,9,10]}$ or perhaps in cases of spinal trauma. ${ }^{[1-13]}$

Plastination, a technique used for preserving biological tissue, was invented by von Hagens in the 1980s ${ }^{[14]} \mathrm{It}$ has been widely adopted around the world as a method of preserving donated human tissue for the purposes of research and education. ${ }^{[15]}$ The technique of E12 sheet plastination, where thin, individual slices of tissue are preserved, allows preserved tissue to be visualised in cross-section. ${ }^{[16,17]}$ Sometimes sections are prepared in series that allow users to identify structures as they pass along or through anatomical regions. E12 sheet plasti- 
nates have the added benefit over standard plastinated material that they can allow visualisation of a detailed cross-section through anatomical structures; large plastinates are non-malleable and do not allow movement or reflection of tissue to access or visualise deep anatomical structures. ${ }^{[15]}$ E12 sheet plastinates also preserve delicate anatomical structures that may be of risk of damage from handling, such as with standard, non-plastinated dissections. ${ }^{[15]}$ E12 sheet plastination has previously been used to investigate various morphological regions such as the posterior atlanto-occipital interspace and supraspinous ligaments, ${ }^{[18-20]}$ but not for studying meniscoid anatomy.

Identifying intra-articular meniscoids with E-12 sheet plastination may facilitate our understanding of their morphology and functional significance. In addition, if meniscoids are able to be visualised using E12 sheet plastination then it will provide a visual resource that can be utilised as an educational tool for teaching clinicians and researchers about these structures. The aim of this study was therefore to establish if intra-articular spinal meniscoids could be identified on E12 sheet plastinates, and to determine whether E12 plastinated sections could be reliably utilised to assist in assessing the presence or absence of spinal meniscoids.

\section{Materials and Methods}

E12 sheet plastinates from two donated female cadavers (aged 65 and 86 years) that had undergone plastination at the Otago School of Medical Sciences (Dunedin, New Zealand) were examined. The E12 sections were prepared according to the methodology outlined by Sora $(2007)^{[17]}$ and Sora and Cook $(2007)^{[16]}$. Donated cadavers were utilised in accordance with institutional ethical approval under the Human Tissue Act (2008) of New Zealand and prior to plastination were embalmed in accordance with mortuary protocol using ethanol and water-based solutions.

One cadaver was sectioned entirely in the sagittal plane, and the other in the transverse plane. Each E12 plastinated section was 2 to $3 \mathrm{~mm}$ in thickness. There were 175 transverse E12 plastinated sections available that included the location of all zygapophyseal and atlantoaxial joints for the length of the vertebral column, and 20 sagittal E12 plastinated sections that included these same joints.

Each individual E12 plastinated section that included zygapophyseal or lateral atlantoaxial joints was photographed on a light-box. Photographs were taken using a tripod-mounted digital camera (Powershot G10 14.7 megapixel, Canon Inc., Tokyo, Japan) fitted with a macro lens. Resulting digital images were then inspected under magnification on a computer (2012 MacBook Pro,

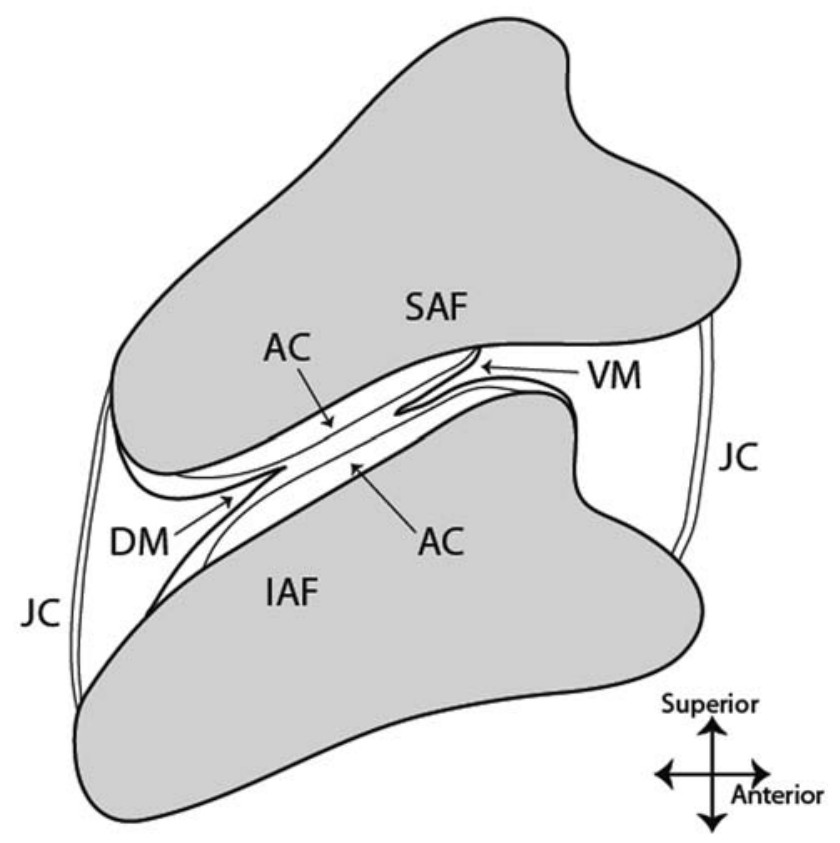

Figure 1. Schematic representation of sagittal section through mid cervical spine zygapophyseal joint. Modified from Friedrich et al. (2008). ${ }^{[8]}$ AC: articular cartilage; DM: dorsal meniscoid; IAF: inferior articular facet; JC: joint capsule; SAF: superior articular facet; VM: ventral meniscoid.

Apple Inc, Cupertino, CA, USA) using Adobe Illustrator CS6 (Adobe Systems Inc., San Jose, CA, USA). The digital images were then inspected following a three-step process. First, the location of individual zygapophyseal and lateral atlantoaxial joints was identified. Second, the articular cavity and surfaces of each joint were identified so as to allow for positive identification of the potential space that meniscoids would likely inhabit if they were present. Third, individual joints were then examined for meniscoids. These were positively identified as structures originating from the synovial membrane of the articular capsule then extending into the joint cavity, to lie positioned between the two articular surfaces of the joint. Identification of meniscoids was based on criteria from previous studies. ${ }^{[1,21]}$

\section{Results}

In total, 281 individual photographs were taken and assessed including 175 digital photographs taken of the transverse E12 sections and 106 digital photographs of sagittal E12 plastinated sections. As a single sagittal E12 plastinated section of the vertebral column was too large to photograph as a single shot in high resolution (approximately $1.2 \mathrm{~m}$ long), multiple photographs had to be taken along the length of each E12 section to ensure the entire length of the vertebral column was captured. 

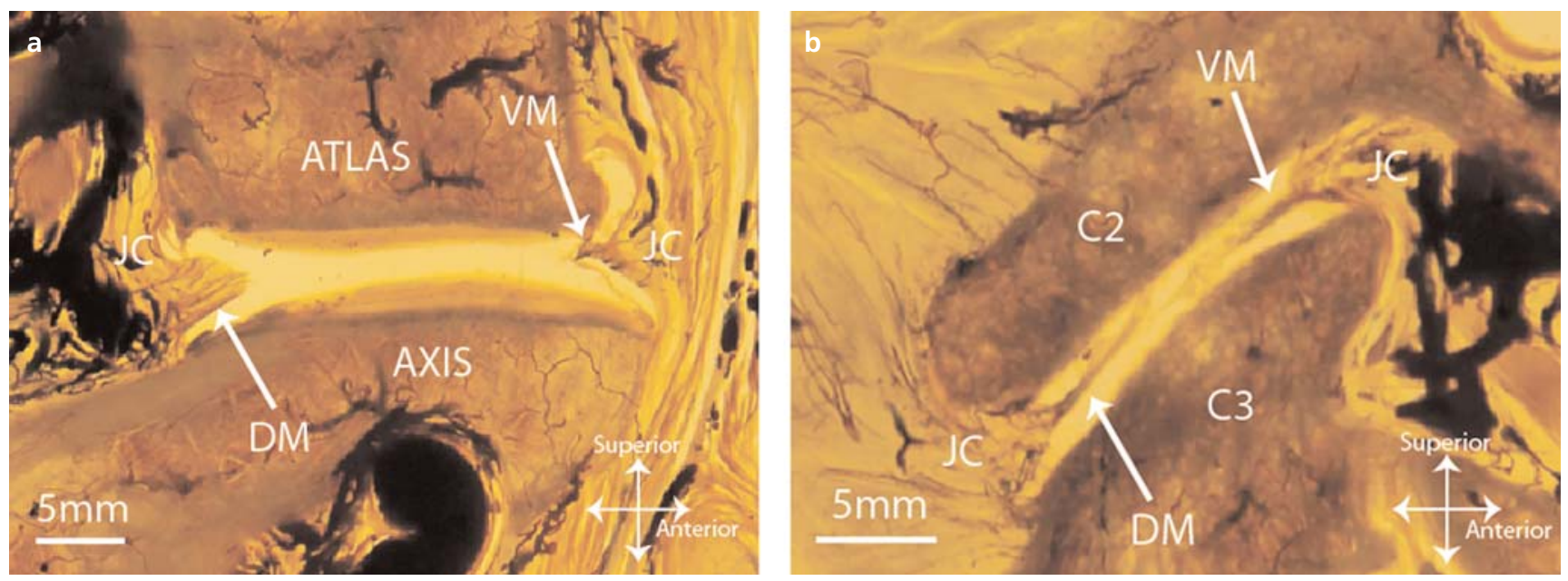

Figure 2. Digital photographs of E12 sheet plastinated sagittal sections of (a) a right lateral atlantoaxial joint, and (b) a right C2-3 zygapophyseal joint. DM: dorsal meniscoid; JC: joint capsule; VM: ventral meniscoid.

\section{Identification of meniscoids}

From the 106 images of sagittal sections, 14 joints (including four lateral atlantoaxial joints) were positively identified in the cervical spine, and 24 in the thoracic spine. From the 14 joints in the cervical region, 24 individual cervical zygapophyseal and lateral atlantoaxial joints were identified containing meniscoids. This included four joints with one meniscoid, and ten joints (including all atlantoaxial joints) with two meniscoids (Figures 2a and b). In the 24 thoracic joints, 32 menis- coids were identified with eight joints containing one meniscoid, and 12 joints containing two meniscoids (Figure 3a). Four thoracic joints had no meniscoid. Lumbar spine joints could not be visualised effectively on sagittal sections because of the sagittal orientation of the joint and articular surface orientation.

In the 175 transverse sections images, articular cavities of joints cephalad to T6 could not be effectively visualised on transverse sections due to articular surface orientation. In the low thoracic spine 14 joints could be

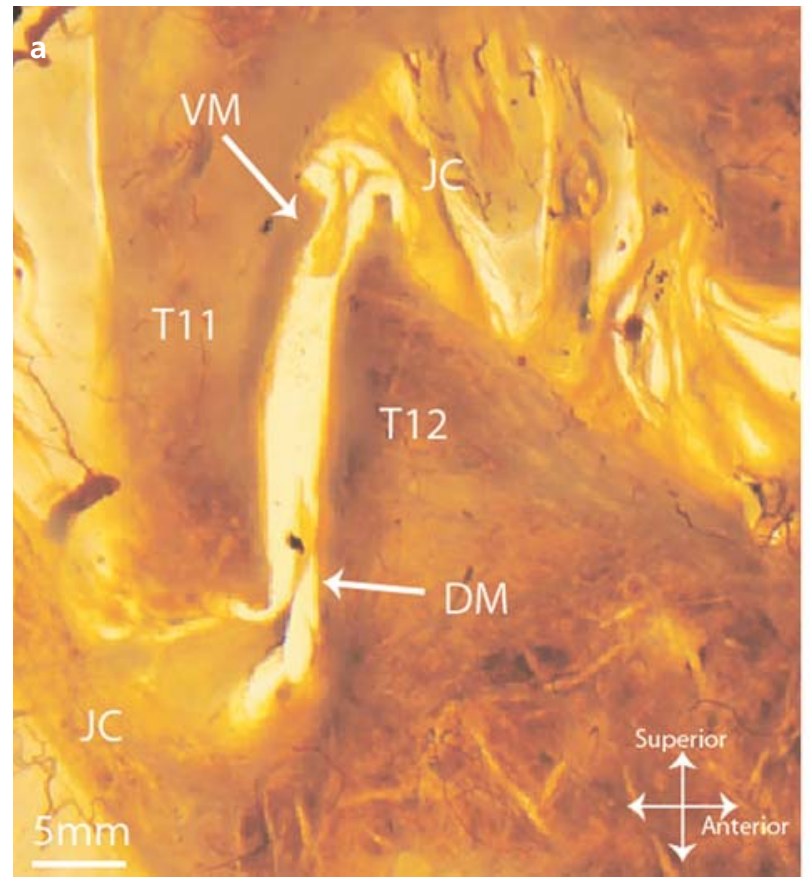

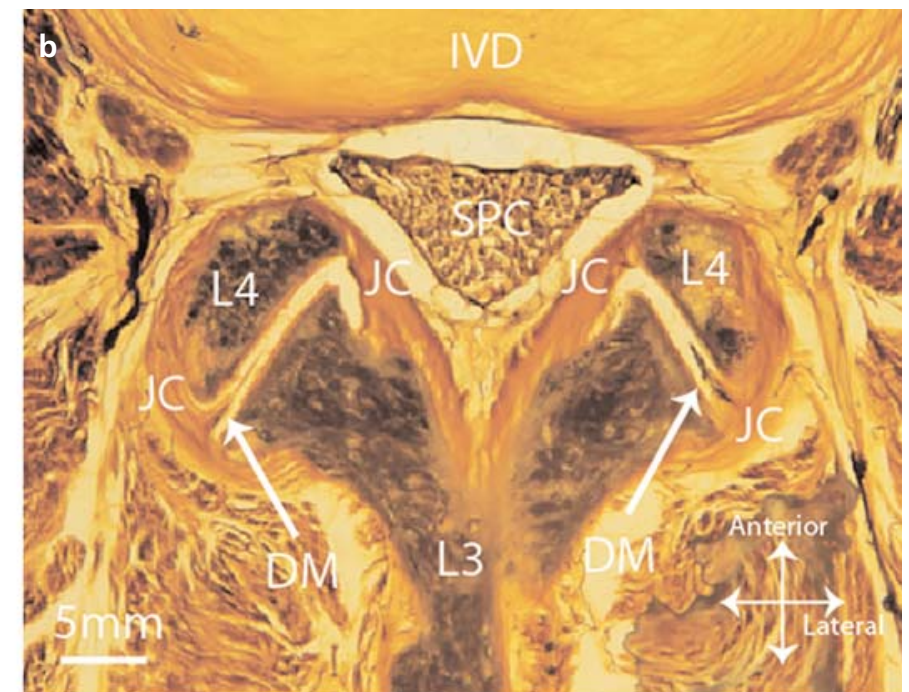

Figure 3. Digital photographs of E12 sheet plastinated sections including (a) a sagittal section of a right T11-12 zygapophyseal joint, and (b) a transverse section of L3-4 zygapophyseal joints. DM: dorsal meniscoid; IVD: intervertebral disc; JC: joint capsule; SPC: spinal cord; VM: ventral meniscoid. 
identified, containing 14 meniscoids including eight joints with one meniscoid, and three joints with two meniscoids; three joints had no meniscoids. In the lumbar region, ten lumbar zygapophyseal joints were identified; four joints had one meniscoid and four joints two meniscoids (Figure 3b), with two joints having no meniscoids.

\section{Incidence of meniscoids}

From the joints that were accurately identified on E12 sheet plastinated sections, meniscoids were found in all atlantoaxial and cervical joints, $78.9 \%$ of thoracic joints and $80 \%$ of lumbar joints.

\section{Discussion}

This study has identified intra-articular spinal meniscoids throughout the length of the vertebral column using E12 sheet plastinated sections in the transverse and sagittal planes, in the lateral atlantoaxial and cervical, thoracic and lumbar zygapophyseal joints. Furthermore, this study has provided information about which section orientations allow for optimal visualisation of meniscoids in different regions of the spine: lateral atlantoaxial, cervical and thoracic meniscoids are best identified on sagittal E12 plastinated sections, while meniscoids cephalad of T6 (low thoracic, lumbar) are best visualised on transverse sections.

This study validates the use of E12 plastinated sheets for the identification of meniscoid anatomy within the atlantoaxial and zygapophyseal joints throughout the length of the vertebral column, indicating that these sections have the potential of being able to be used as an educational tool to demonstrate the location and morphology of spinal meniscoids in teaching gross anatomy. In addition, if future clinical research implicates meniscoids as significant in spinal pathology, these findings suggest that E12 sheet plastinated sections may also be utilised in the clinical anatomy education of healthcare professionals to convey the morphology and location of these structures within the spine.

The incidence of meniscoids in the two cadavers studied is higher than frequencies reported in other studies; previous reports suggest that meniscoids are apparent in all atlantoaxial joints, ${ }^{[4]} 86 \%$ of cervical joints, ${ }^{[3]}$ $62 \%$ of thoracic joints ${ }^{[22]}$ and all lumbar spine joints. ${ }^{[5]}$ Our results include meniscoids being identified in all atlantoaxial and cervical joints, and $78.9 \%$ and $80 \%$ of thoracic and lumbar zygapophyseal joints, respectively. This indicates E12 sheet plastination could potentially be utilised in studies to examine the frequency of meniscoid presence or absence in synovial joints of the spine.
It is unclear whether meniscoid presence throughout the vertebral column is related to sex.

The ability to visualise meniscoids on E12 sheet plastinated sections may be useful in studies exploring meniscoid morphology to comprehensively investigate the anatomy of these structures throughout the length of the vertebral column. Using this methodology may facilitate an understanding of their precise role in musculoskeletal spinal pathology, such as whiplash associated disorder ${ }^{[4]}$ or acute locked back. ${ }^{[9]}$ It may also provide useful information for how meniscoid morphology may differ between the regions, for instance between the cervical and lumbar spine. A potential benefit of examining meniscoids using E12 plastinated sections includes the possibility of being able to assess articular cartilage degeneration in a cross section through the meniscoid and articular cartilage; in this way it may be possible to study how meniscoid presence may relate to articular cartilage degeneration, and improve our understanding of the potential role of meniscoids in zygapophyseal joint degeneration. ${ }^{[3,4]}$

At some spinal levels, it was not possible to visualise a joint cavity in transverse sections or in sagittal sections. Consequently, it was therefore impossible to accurately identify whether a meniscoid were present in these joints. This affected the identification of lumbar meniscoids in the sagittal sections, and cephalad joints from T6 in the transverse sections. The study did accurately identify meniscoids throughout the length of the vertebral column, however it should be noted that E12 plastinated sections are required in both the sagittal and transverse planes to achieve this.

During processing to create E12 sheet plastinated specimens, a very small amount of tissue is inadvertently destroyed as a result of the blade cutting through tissue. This means there may have been some instances where small meniscoids were destroyed during processing, and these were subsequently unable to be identified once E12 plastinated sheets were produced. However as the principle aim of this study was to identify meniscoids, any false-negative results (i.e., not identifying meniscoids in some joints where they actually may have been located before processing) do not invalidate our observations. Furthermore, there was a very high presence of thoracic and lumbar meniscoids in addition to meniscoids being visible in all atlantoaxial and cervical joints, indicating that the risk of destroying meniscoids while processing E12 sheet plastinated sections may be very small.

Shrinkage of cadaveric tissue that occurs secondary to dehydration from embalming in ethanol and from the processes involved in plastination has previously been 
reported in nervous and muscle tissue. ${ }^{[2,24]}$ The possibility of shrinkage of meniscoid tissue cannot be excluded, therefore it is unclear whether the results of this study can be generalized to studies that utilize fresh or nonethanol embalmed cadavers. In addition, the process of degreasing may have affected the constitution of fatty or adipose meniscoids that purportedly contribute to a high proportion of total meniscoids $(61.1 \%),{ }^{[8]}$ though any such affect would be difficult to quantify. Given the combined effects of dehydration and degreasing may both decrease the likelihood of positively identifying meniscoids, the results may potentially represent an underestimation of actual meniscoid prevalence.

\section{Limitations}

Only two sets of E12 plastinated sections from elderly cadavers were used for this study; this was because we could only undertake this project with the resources that were available. Because of the limited number of cadavers, and because the joints from the whole length of each spine were not able to be assessed due to the inability to visualise some joints through section orientation, we are unable to reliably comment on whether the uncommonly high incidence of thoracic and lumbar meniscoids reported in this study is meaningful. However, results suggest that a cadaver that is preserved using E12 sheet plastination in either the transverse or sagittal plane will potentially yield a high proportion of meniscoids that can be identified and examined. It is unknown whether coronal E12 sections would provide similar results.

\section{Conclusion}

This small study demonstrates that intra-articular spinal meniscoids in lateral atlantoaxial and cervical, thoracic and lumbar zygapophyseal joints can successfully be identified on E12 sheet plastinated sections that are in the transverse and sagittal planes. The high frequency of identified meniscoids in each region of the spine on E12 sheet plastinates suggest they may be reliable for use in studies assessing meniscoid presence or absence. E12 plastinated sections can therefore be utilised in research and education to further explore the morphology of spinal meniscoids and determine a better understanding of their morphology and potential role in spinal pathologies.

\section{Acknowledgements}

This work was supported by the Otago School of Medical Sciences, University of Otago, and the Faculty of Health and Medicine, The University of Newcastle.
Scott Farrell is supported by an Australian Post-graduate Award scholarship. The authors are grateful for the technical assistance of $\mathrm{Mr}$ Chris Smith and Ms Rachna Luthra, Department of Anatomy, Otago School of Medical Sciences. The authors would also like to thank those donors who so graciously gifted their bodies to the Otago School of Medical Sciences body donor programme.

\section{References}

1. Mercer S, Bogduk N. Intra-articular inclusions of the cervical synovial joints. J Rheumatol 1993;32:705-10.

2. Webb A, Collins P, Rassoulian H, Mitchell B. Synovial folds - a pain in the neck? Man Ther 2011;16:118-24.

3. Farrell SF, Osmotherly PG, Cornwall J, Rivett DA. The anatomy and morphometry of cervical zygapophyseal joint meniscoids. Surg Radiol Anat 2014; DOI 10.1007/s00276-014-1406-3

4. Farrell SF, Osmotherly PG, Cornwall J, Rivett DA. Morphology and morphometry of the atlantoaxial joint meniscoids. Anat Sci Int 2015; DOI 10.1007/s12565-015-0276-z

5. Bogduk N, Engel R. The menisci of the lumbar zygapophyseal joints. J Anat 1982;135:795-809.

6. Webb A, Darekar A, Sampson M, Rassoulian H. Synovial folds of the lateral atlantoaxial joints: in vivo quantitative assessment using magnetic resonance imaging in healthy volunteers. Spine (Phila $\mathrm{Pa}$ 1976) 2009;34:E697-702.

7. Bogduk N, Engel R The menisci of the lumbar zygapophyseal joints. A review of their anatomy and significance. Spine (Phila $\mathrm{Pa}$ 1976) 1984;9:454-60.

8. Friedrich KM, Reiter G, Pretterkleiber ML, Pinker K, Friedrich M, Trattnig S, Salomonowitz E. Reference data for in vivo magnetic resonance imaging properties of meniscoids in the cervical zygapophyseal joints. Spine (Phila Pa 1976) 2008;33:e778-83.

9. Bogduk N, Jull G. The theoretical pathology of acute locked back: a basis for manipulative therapy. Man Med 1985;1:78-82.

10. Bogduk N. Clinical anatomy of the lumbar spine and sacrum. 4th ed. Edinburgh: Elsevier; 2005.

11. Schonstrom N, Twomey L, Taylor J. The lateral atlantoaxial joints and their synovial folds: an in vitro study of soft tissue injuries and fractures. J Trauma 1993;35:886-92.

12. Taylor J, Taylor M. Cervical spine injuries: an autopsy of 109 blunt injuries. J Musculoskelet Pain 1996;4:61-79.

13. Bogduk N. On cervical zygapophyseal joint pain after whiplash. Spine (Phila Pa 1976) 2011;36:S194-9.

14. von Hagens G, Tiedemann K, Kriz W. The current potential of plastination. Anat Embryol 1987;175:411-21.

15. Cornwall J. The diverse utility of wet prosections and plastinated specimens in teaching gross anatomy in New Zealand. Anat Sci Educ 2011;4:269-74.

16. Sora MC, Cook P. Epoxy plastination of biological tissue: E12 technique. Journal of Plastination 2007;22:31-9.

17. Sora MC. Epoxy plastination of biological tissue: E12 ultra-thin technique. Journal of Plastination 2007;22:40-5. 
18. Phillips MN, Nash LG, Barnett RJ, Nicholson HD, Zhang M. The use of confocal microscopy for the examination of E12 sheet plastinated human tissue. Journal of Plastination 2002;17:12-6.

19. Nash LG, Nicholson HD, Lee AS, Johnson GM, Zhang M. Configuration of the connective tissue in the posterior atlantooccipital interspace: a sheet plastination and confocal microscopy study. Spine (Phila Pa 1976) 2005;17:1359-66.

20. Johnson GM, Zhang M. Regional differences within the human supraspinous and interspinous ligaments: a sheet plastination study. Eur Spine J 2002;11:382-8.

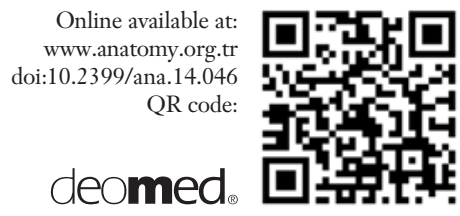

21. Inami S, Kaneoka K, Hayashi K, Ochiai N. Types of synovial fold in the cervical facet joint. J Orthop Sci 2000;5:475-80.

22. Schulte T, FIiller T, Struwe P, Liem D, Bullman V. Intra-articular meniscoid folds in thoracic zygapophyseal joints. Spine (Phila Pa 1976) 2010;E191-7.

23. Brown M, Reed R, Henry R. Effects of dehydration mediums and temperature on total dehydration time and tissue shrinkage. Journal of Plastination 2002;17:28-33.

24. Cutts A. Shrinkage of muscle fibres during the fixation of cadaveric tissue. J Anat 1988;160:75-78.

\section{Correspondence to: Scott F. Farrell}

School of Health Sciences, Faculty of Health and Medicine, The University of Newcastle, HA06 Hunter Building, Callaghan Newcastle, NSW 2308, Australia

Phone: +61 24921 7374; Fax: +61249217053

e-mail: scott.farrell@newcastle.edu.au

Conflict of interest statement: No conflicts declared.

This is an open access article distributed under the terms of the Creative Commons Attribution-NonCommercial-NoDerivs 3.0 Unported (CC BY-NCND3.0) Licence (http://creativecommons.org/licenses/by-nc-nd/3.0/) which permits unrestricted noncommercial use, distribution, and reproduction in any medium, provided the original work is properly cited. Please cite this article as: Farrell SF, Osmotherly PG, Rivett DA, Cornwall J. Can E12 sheet plastination be used to examine the presence and incidence of intra-articular spinal meniscoids? Anatomy 2015;9(1):13-18. 